\title{
An Efficient Heparin Affinity Column Purification Method Coupled with Ultraperformance Liquid Chromatography for the Quantification of Native Lactoferrin in Breast Milk
}

\author{
Huizhi Yuan $\mathbb{D}^{1}{ }^{1} \mathrm{Na} \mathrm{Li},{ }^{2}$ Yiping Xun, ${ }^{3}$ Lin Wang, ${ }^{1}$ Xiaoying Feng, ${ }^{3}$ Yongxia Wang, \\ Yajie Tao, ${ }^{4}$ and Shijie Wang $\mathbb{1}^{1,3}$ \\ ${ }^{1}$ College of Food and Biology, Hebei University of Science and Technology, Shijiazhuang, Hebei 050018, China \\ ${ }^{2}$ College of Biological Science and Engineering, Hebei University of Engineering, Handan, Hebei 056107, China \\ ${ }^{3}$ Shijiazhuang Junlebao Dairy Co. Ltd., Shijiazhuang, Hebei 050221, China \\ ${ }^{4}$ Handan First Hospital, Handan, Hebei 056002, China \\ Correspondence should be addressed to Shijie Wang; mrshjwang@163.com
}

Received 9 June 2021; Revised 13 August 2021; Accepted 16 August 2021; Published 27 August 2021

Academic Editor: Daniel Cozzolino

Copyright $\odot 2021$ Huizhi Yuan et al. This is an open access article distributed under the Creative Commons Attribution License, which permits unrestricted use, distribution, and reproduction in any medium, provided the original work is properly cited.

Lactoferrin (LF) is a bioactive multifunctional protein and found in the highest amounts in human milk. Several methods can be used to quantify LF. However, quantification of native LF has garnered relatively little interest to date. This study aimed to develop a novel efficient two-step method for quantifying native LF in breast milk. During the analysis, LF was first extracted with phosphate buffer ( $\mathrm{pH}$ 5.0), purified using a heparin affinity column. Subsequently, LF was detected using ultraperformance liquid chromatography (UPLC) at a wavelength of $201 \mathrm{~nm}$. A linear calibration curve was obtained in the range of 5-200 mg/L. The limit of detection and limit of quantitation were $1 \mathrm{mg} / \mathrm{L}$ and $5 \mathrm{mg} / \mathrm{L}$, respectively, indicating that the validated method could be employed to quantify LF in breast milk. Compared with previous HPLC methods, this method demonstrated several remarkable advantages, including simple operation, low-cost detection, and high accuracy. Hence, the results demonstrate an efficient method that can be employed commercially to purify and analyze LF in human milk samples.

\section{Introduction}

Lactoferrin (LF) is a multifunctional globular glycoprotein that can be characterized as a member of the transferrin family $[1,2]$. It is an iron-binding protein composed of a single-chain polypeptide with two globular lobes [3]. The polypeptide chain consists of approximately $600-700$ amino acid residues and has a molecular weight of $80 \mathrm{kDa}$ [4]. LF exhibits a variety of functional properties due to its unique structural features. The antibacterial activity is one of the most critical functions of LF [5]. LF also mediates other biological activities, such as regulation of iron transport, immune system, transcription, proteolysis, and enzyme activity, along with antitumor and anti-inflammatory effects [6]. The richest sources of LF are breast and bovine milk. However, many differences have been observed in LF present in human and bovine milk. The concentration of LF in milk varies significantly with the lactation period and species $[7,8]$. LF concentration in bovine milk (approximately $0.8-1.0 \mathrm{~g} / \mathrm{L}$ in colostrum and $0.03-0.49 \mathrm{~g} / \mathrm{L}$ in mature milk) [9] is lower than that in human milk and its colostrum (approximately $5.0-7.0 \mathrm{~g} / \mathrm{L}$ in colostrum and $1.0-3.0 \mathrm{~g} / \mathrm{L}$ in mature milk) [10]. Structurally, LF in human and bovine sources exhibits approximately $70 \%$ sequence homology. Furthermore, LF in human and bovine milk is composed of 691 and 696 amino acids, respectively [11]. Due to differences between bovine LF and human LF, accurate and rapid determination of LF in human milk is of great significance for nutritional research and commercial design of infant formula.

Common quantification methods can be classified into immunological and nonimmunological methods [12]. Immunological methods include enzyme-linked 
immunosorbent assay (ELISA) and surface plasmon resonance-based immunosensors [13]. Although immunological methods exhibit high selectivity and sensitivity, they have poor reproducibility [14]. Nonimmunological techniques such as ultraperformance liquid chromatography-tandem mass spectrometry (UPLC-MS), reversed-phase high-performance liquid chromatography (RP-HPLC), and capillary electrophoresis (CE) have also been reported [6]. UPLC-MS enables highly sensitive and selective detection of LF using multiple reaction monitoring modes based on signature peptides [12]. RP-HPLC can be used for the determination of native LF. However, a sensitive detection can only be observed when evaluating dairy products with high LF content $[15,16]$. CE is widely used for protein analysis; however, it is limited by capillary, voltage, and other conditions. Hence, it may not be sensitive enough to separate proteins with small differences in molecular weight [17]. Intact LF remains indistinguishable from its denatured form when analyzed using chromatographic techniques, which may lead to the overestimation of LF.

Heparin, a sulfated polysaccharide belonging to the glycosaminoglycan family, is used to enrich native LF [18]. Heparin has the highest negative charge density among known biological macromolecules [19]. Therefore, heparin exhibits a high binding affinity to various proteins, including LF but excluding $\beta$-lactoglobulin, $\alpha$-lactalbumin, and serum albumin [16]. Heparin affinity column has been widely used for the purification of LF due to its special properties. In the study performed by Lutaty et al. [20], the breast milk samples were loaded onto a heparin affinity column and washed and eluted with different salt concentrations. Subsequently, the protein was collected, thereby improving the purity of the LF-enriched fraction. Similarly, LF was purified from transgenic milk and bovine milk retentate using affinity chromatography as described by Parc et al. [21].

Herein, the objective of the study was to develop an efficient method using heparin affinity column purification coupled with UPLC detection for the determination of native LF in breast milk. A heparin affinity column was employed for the purification of LF by optimizing extraction conditions and elution conditions.

\section{Materials and Methods}

2.1. Reagents and Instruments. Heparin affinity column was purchased from Meizheng Bio-Tech Co., Ltd. (Beijing, China). Disodium hydrogen phosphate dodecahydrate, sodium dihydrogen phosphate dihydrate, sodium chloride, and trifluoroacetic acid were purchased from Damao Chemical Reagent Factory (Tianjin, China). Acetonitrile and methanol were purchased from Merck (Darmstadt, Germany). Human LF $(\geq 85 \%)$ was purchased from SigmaAldrich (St. Louis, MO, USA). Deionized water was purified using the Milli-Q water purification system (Millipore, MA, USA). HPLC grade reagents were used in this study.

2.2. Sample Collection. Healthy mothers with ages ranging from 20 to 35 years participated in this study. Women with physical or mental disorders and those under nutritional or drug intervention were excluded from this study. Each participant submitted written informed consent prior to inclusion in the study. A total of three colostrum, two transitional milk, and 12 mature milk samples were collected using a manual suction pump between 09:00 a.m. and 11:00 a.m. from day 1 to day 330 after delivery. After collection, the samples were frozen and stored at $-80^{\circ} \mathrm{C}$ until further analysis.

2.3. Dynamic Adsorption Analysis Using a Heparin Affinity Column. The working principle of the heparin affinity column is depicted in Figure 1(a). Continuous flow adsorption studies were conducted using an adsorption column with an inner diameter of $1.5 \mathrm{~cm}$ and a height of $12 \mathrm{~cm}$. Before the sample injection, the column was flushed with buffer. During the process of injection, the sample was added to the top, which flowed through the column owing to the effect of gravitational force. The effluent samples were collected at specified times and analyzed using UPLC.

The dynamic behavior of the columns was predicted using logistic models. The linearized model for a singlecomponent system was expressed using the following equation: $\left.y=A_{2}+\left(A_{1}-A_{2}\right) /\left(1 x / x_{0}\right) p\right)$.

2.4. Sample Extraction. A total of $1 \mathrm{~mL}$ of breast milk was centrifuged at $10000 \mathrm{rpm}$ for $8 \mathrm{~min}$ at $4^{\circ} \mathrm{C}$ [6]. After centrifugation, the supernatant was transferred to a new centrifuge tube. Buffer solution A $\left(99.38 \mathrm{mmol} / \mathrm{L} \mathrm{Na}_{2} \mathrm{HPO}_{4} \cdot 12 \mathrm{H}_{2} \mathrm{O}\right.$ and $0.61 \mathrm{mmol} / \mathrm{L} \mathrm{NaH}_{2} \mathrm{PO}_{4} \cdot 2 \mathrm{H}_{2} \mathrm{O}, \mathrm{pH} 5.0$ ) was added, followed by mixing the sample using a vortex mixer for $2 \mathrm{~min}$. The sample extract was loaded onto the column as a loading solution.

2.5. Sample Cleanup. A total of $5 \mathrm{ml}$ of buffer solution A was added to the heparin affinity column. The sample extract was added after treatment with the buffer. After the sample solution was eluted completely, the column was rinsed with $10 \mathrm{~mL}$ of buffer solution $\mathrm{B}\left(99.38 \mathrm{mmol} / \mathrm{L} \mathrm{Na}_{2} \mathrm{HPO}_{4} \cdot 12 \mathrm{H}_{2} \mathrm{O}\right.$, $0.61 \mathrm{mmol} / \mathrm{L} \mathrm{NaH} \mathrm{PO}_{4} \cdot 2 \mathrm{H}_{2} \mathrm{O}$, and $100 \mathrm{mmol} / \mathrm{L} \mathrm{NaCl}$ ). All effluents were discarded. Finally, the column was eluted with $4 \mathrm{~mL}$ of eluent $\left(99.38 \mathrm{mmol} / \mathrm{L} \mathrm{Na}_{2} \mathrm{HPO}_{4} \cdot 12 \mathrm{H}_{2} \mathrm{O}, 0.61 \mathrm{mmol} / \mathrm{L}\right.$ $\mathrm{NaH}_{2} \mathrm{PO}_{4} \cdot 2 \mathrm{H}_{2} \mathrm{O}$, and $1 \mathrm{~mol} / \mathrm{L} \mathrm{NaCl}$ ) [22]. The eluent was collected and centrifuged at $9000 \mathrm{rpm}$ for $5 \mathrm{~min}$ before UPLC analysis.

2.6. LC Conditions. The ACQUITY UPLC H-Class PLUS core system (Waters, MA, USA) includes a quaternary solvent manager (pump), sample manager-flow through needle (SMFTN), column heater, detector (PDA detector), and ACQUITY UPLC BEH300 C4 column $(2.1 \mathrm{~mm} \times 100 \mathrm{~mm}, 1.7 \mu \mathrm{m})$. The UPLC system was controlled with Waters ${ }^{\circledR}$ Empower $^{\mathrm{TM}}$ chromatography software. The column temperature was maintained at $60^{\circ} \mathrm{C}$. The UV detection wavelength and the injection amount were maintained at $201 \mathrm{~nm}$ and $10 \mu \mathrm{L}$, respectively. Line $\mathrm{A}$ in the mobile phase involved $0.1 \%$ trifluoride acetic acid mixed in water, whereas line B involved $0.09 \%$ trifluoroacetic acid mixed in acetonitrile solution. Gradients were set as shown in Table 1. 


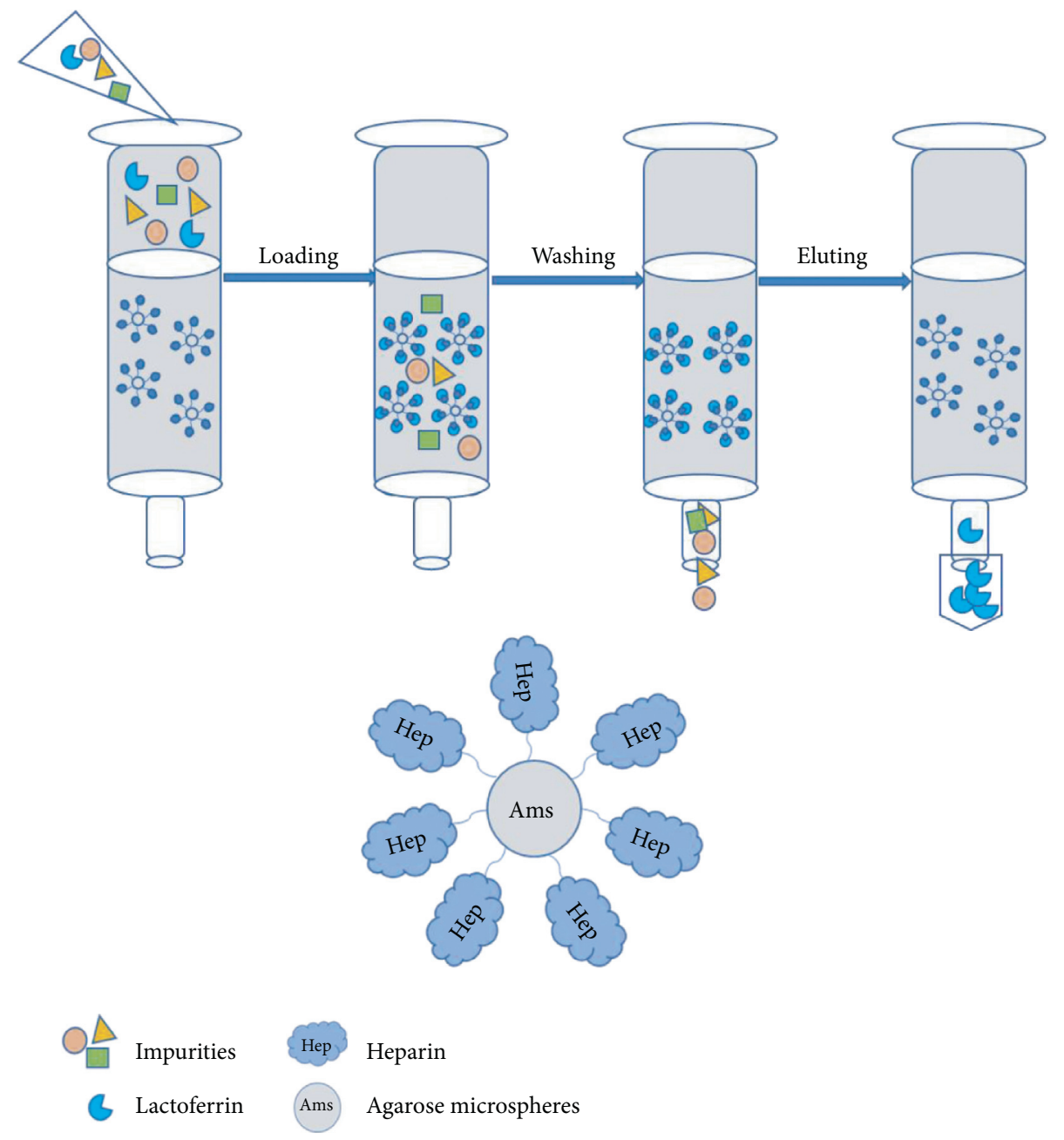

(a)

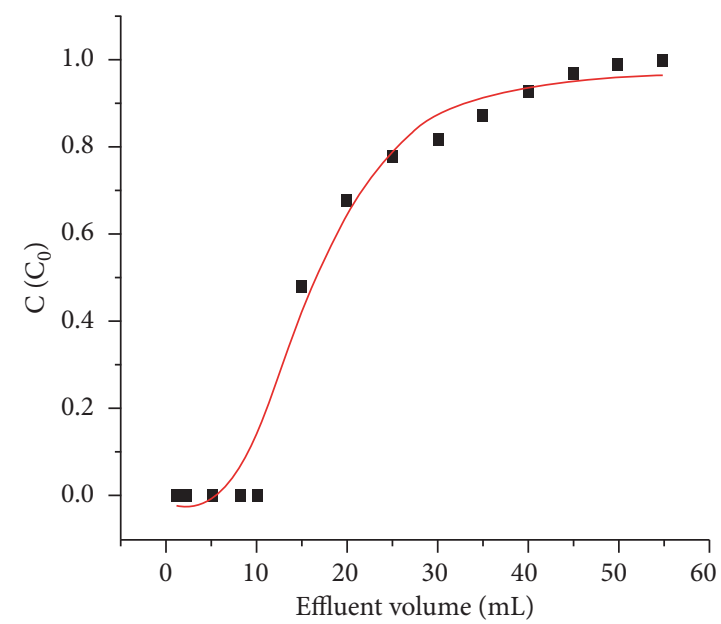

(b)

FIGURE 1: Characteristics of the heparin affinity column. (a) The packing structure and working principle of the heparin affinity column. (b) Breakthrough curve of the heparin affinity column.

2.7. Statistical Analysis. All experiments were performed in triplicate, and the results are expressed as mean \pm standard deviation. Origin 9.0 (OriginLab Corporation, USA) was used to obtain scientific graphs, and SPSS Statistics 22.0 was used to determine significant differences between samples with $p<0.05$. 
TABLE 1: Optimization of gradient elution.

\begin{tabular}{lccc}
\hline Time $(\mathrm{min})$ & Line A (\%) & Line B (\%) & Flow rate $(\mathrm{mL} / \mathrm{min})$ \\
\hline 0 & 95 & 5 & 0.45 \\
1.5 & 62 & 38 & 0.45 \\
2.5 & 62 & 38 & 0.45 \\
5.5 & 55 & 45 & 0.45 \\
5.6 & 5 & 95 & 0.45 \\
7.0 & 5 & 95 & 0.45 \\
7.1 & 95 & 5 & 0.45 \\
9.0 & 95 & 5 & 0.45 \\
\hline
\end{tabular}

The flow rate, time, and mobile phase ratio of gradient elution were appropriately adjusted according to factors such as peak output and peak shape to complete the optimization of gradient elution conditions.

\section{Results}

3.1. Breakthrough Curve of the Heparin Affinity Column. Figure 1(b) shows the breakthrough curve determined during the continuous adsorption experiment performed using the heparin affinity column. The breakthrough curve showed an exceptionally good shape, which indicated that LF finally reached adsorption equilibrium with effective adsorption on the adsorption column.

3.2. Optimization of Chromatographic Conditions. The choice of wavelength can improve the detection of human LF (HLF) by maximizing the sensitivity and minimizing interferences. As shown in Figures 2(a) and 2(b), HLF was detected at a wavelength ranging from 200.5 to $201.7 \mathrm{~nm}$. According to the peak responsivity, $201 \mathrm{~nm}$ was selected as the detection wavelength.

Some studies have demonstrated a high UV response of $\mathrm{HLF}$ at $280 \mathrm{~nm}[23,24]$. Hence, the wavelength was determined by comparing the UV absorbance measured at $201 \mathrm{~nm}$ and $280 \mathrm{~nm}$. The UV absorbances measured at 201 and $280 \mathrm{~nm}$ were monitored for the determination of the protein elution profile. As shown in Figure 2(c) and Supplementary Table 1, the relationship between the relative protein concentration in human milk and the signal observed at $280 \mathrm{~nm}$ was linear. However, many peaks corresponding to impurities were observed in the sample eluent. During the detection of HLF at $201 \mathrm{~nm}$, the response sensitivity was significantly improved due to a better resolution of the HLF peak at the baseline. Therefore, $201 \mathrm{~nm}$ was selected as the detection wavelength.

The choice of the chromatography column can influence the separation of HLF from sample components [25]. Here, a C4 column was selected for the HLF detection.

\subsection{Optimization of the Sample Pretreatment Process}

3.3.1. Effect of the Ratio of the Sample to Buffer Solution A. An appropriate extraction rate is conducive to the extraction of HLF [26]. Considering the extraction efficiency, four dilutions of $1: 20,1: 50,1: 100$, and $1: 200$ were used for analysis, while other variables were set as follows: $\mathrm{pH}$ of buffer solution A was maintained at 7.5. The phosphate concentration in buffer solution A was $100 \mathrm{mmol} / \mathrm{L} . \mathrm{NaCl}$ concentration in buffer solution $\mathrm{B}$ was $100 \mathrm{mmol} / \mathrm{L} . \mathrm{NaCl}$ concentration in the eluent was $1.0 \mathrm{~mol} / \mathrm{L}$. The influence of sample dilution on the measurement of HLF was analyzed. The effect of dilution can be observed in Figure 3(c). At the extraction rate observed with a dilution of $1: 100$, the value was approximately $88 \%$.

3.3.2. Effect of Phosphate Concentrations in Buffer Solution A. The target protein in the sample was extracted using buffer solution A. Retaining the activity of the protein throughout the process was crucial. To study the effect of buffer solution A on HLF activity and extraction efficiency, different concentrations of phosphate $(50,100$, and $200 \mathrm{mmol} / \mathrm{L})$ were tested during the measurement. The results showed that the optimal phosphate concentration was $100 \mathrm{mmol} / \mathrm{L}$. A significant decrease was observed in the LF reaction at all concentrations higher than the optimal phosphate concentration (Figure 3(b)). This might be attributed to the fact that the binding of LF to heparin involved an electrostatic interaction, which could be disrupted with an increase in the ionic strength [16].

3.3.3. Effect of pH Values in Buffer Solution A. $\mathrm{pH}$ of buffer solution A has a significant effect on the structure and stability of LF [27]. In this study, aqueous phase $\mathrm{pH}$ was varied between 3.0 and 9.0 to study the effect of $\mathrm{pH}$ on the HLF extraction. The extraction efficiency was very low at basic $\mathrm{pH}$, but it was found to increase in acidic $\mathrm{pH}$ (Figures 3(c) and 3(f)). Therefore, pH 5.0 was selected to further optimize purification conditions. The thermal stability of LF was severely affected, and it gelled at neutral and alkaline $\mathrm{pH}$ when heated at $80-100^{\circ} \mathrm{C}$ for $5 \mathrm{~min}$ [28]. Under acidic conditions, LF was relatively stable when heated at approximately $\mathrm{pH}$ 3.0-4.0 [28]. This implies that LF exhibits better thermal stability under acidic conditions.

\subsubsection{Effect of $\mathrm{NaCl}$ Concentrations in Buffer Solution B.} The purpose of buffer solution $B$ was to wash out the impurities that were not specifically bound to the heparin affinity column. In this study, different concentrations of $\mathrm{NaCl}(0,50,100,200$, and $300 \mathrm{mmol} / \mathrm{L})$ were selected for testing. The results showed that the reaction of LF was enhanced upon increasing $\mathrm{NaCl}$ concentrations in the range of $0-100 \mathrm{mmol} / \mathrm{L}$ (Figure 3(d)). This might be attributed to the fact that buffer $\mathrm{B}$ washed away nonspecifically bound 


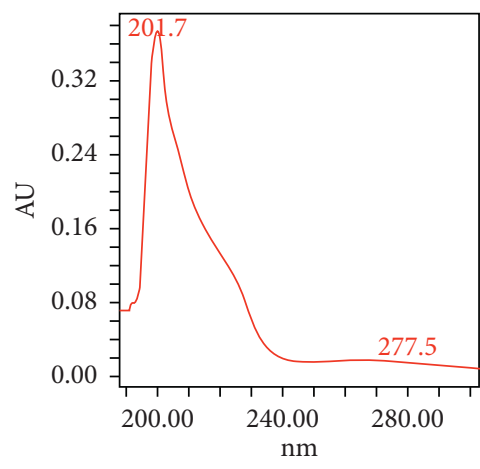

(a)

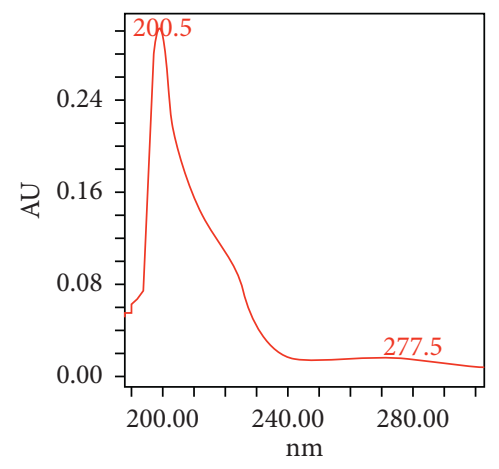

(b)

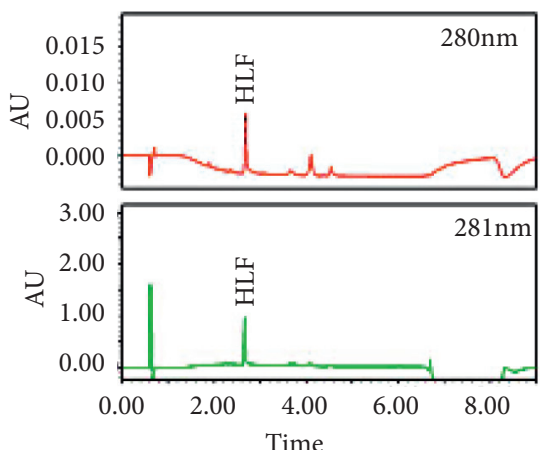

(c)

FIgURe 2: Optimized diagrams of detection wavelength. (a) Spectrogram of human lactoferrin standard solution. (b) Spectrogram of the human lactoferrin sample. (c) Chromatograms of human lactoferrin samples at different wavelengths.

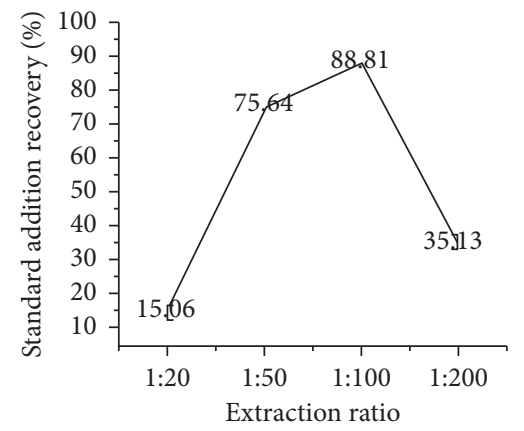

(a)

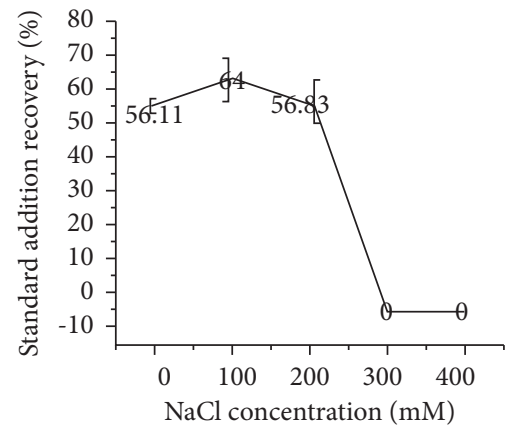

(d)

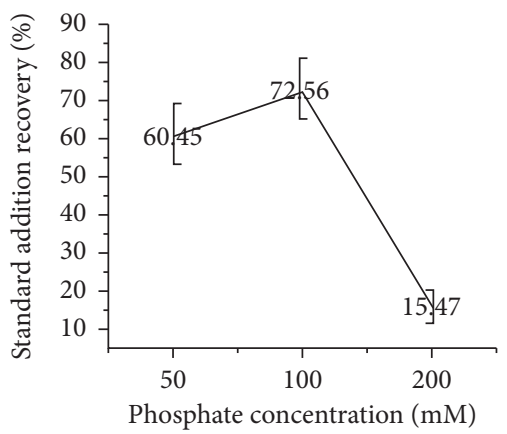

(b)

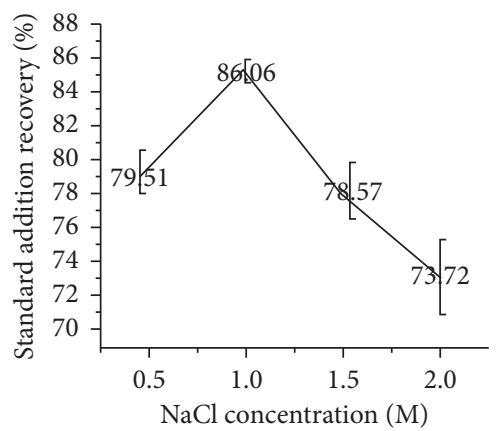

(e)

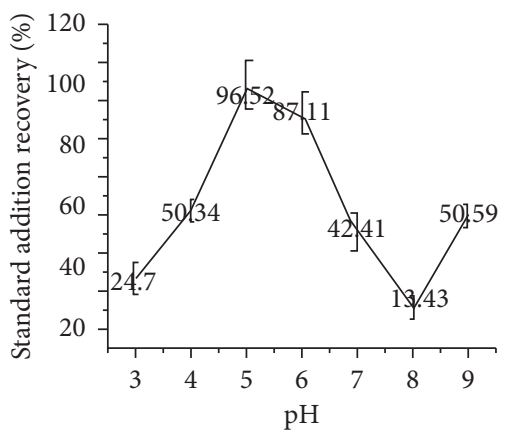

(c)

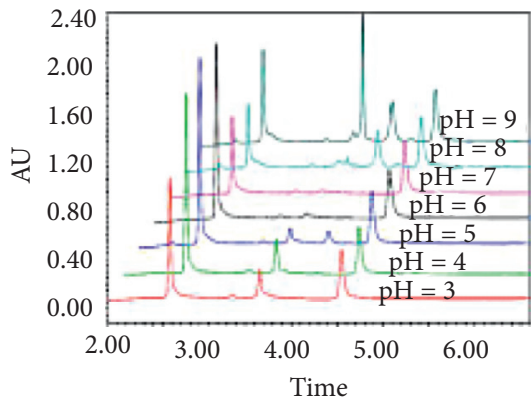

(f)

FiguRE 3: Optimized diagrams of sample pretreatment conditions. (a) Effect of the extraction ratio. (b) Effect of phosphate concentrations in buffer A. (c) Effect of $\mathrm{pH}$ values of buffer A. (d) Effect of $\mathrm{NaCl}$ concentrations in buffer $\mathrm{B}$. (e) Effect of $\mathrm{NaCl}$ concentrations in the eluent. (f) HPLC chromatogram of the human lactoferrin sample (from top to bottom: $\mathrm{pH}=9.0,8.0,7.0,6.0,5.0,4.0$, and 3.0). Data are presented as mean \pm SD.

heterologous impurities, thereby purifying and enriching the target protein. However, the high salt concentration required to elute LF also leads to the release of the bound target protein.

\subsubsection{Effect of $\mathrm{NaCl}$ Concentrations in the Elution Solution.} $\mathrm{NaCl}$ concentration in the elution solution was an important parameter that could influence the desorption of LF from heparin. Therefore, four $\mathrm{NaCl}$ concentrations of $0.5 \mathrm{~mol} / \mathrm{L}$, $1.0 \mathrm{~mol} / \mathrm{L}, 1.5 \mathrm{~mol} / \mathrm{L}$, and $2.0 \mathrm{~mol} / \mathrm{L}$ were used to elute the sample. No elution peak was observed at low physiological salt concentrations, indicating potential adsorption of the protein to the column matrix (data not shown). Higher elution efficiencies of LF were observed with high salt concentrations at a constant elution volume (Figure 3(e)), and $100 \mathrm{mM} \mathrm{NaCl}$ was selected for subsequent extractions.

\subsection{Method Validation}

Linearity. The linearity was checked using samples of standard human LF at six different concentrations 
(5-200 $\mathrm{mg} / \mathrm{L})$. The linear regression equation was determined as follows: $y=16881 x+161391$ with a correlation coefficient $\left(R^{2}\right)$ of 0.9977 (Supplementary Figure 1).

Limit of Detection (LOD) and Limit of Quantitation (LOQ). The LOD and LOQ were $1 \mathrm{mg} / \mathrm{L}$ and $5 \mathrm{mg} / \mathrm{L}$, which were calculated as the lowest concentrations that demonstrated signal-to-noise ratios of 3 and 10 , respectively.

Precision. Intermediate precision was determined, which was defined as the agreement between the test results obtained using the same method performed with identical test material in the same laboratory by the same operators using the same equipment over several days [17]. It was expressed in percentage RSD. To evaluate the intraday and interday precision of the method, a diluent of the breast milk sample was pretreated under the aforementioned optimal test conditions each day for four consecutive days. Results are summarized in Table 2.

Accuracy. The accuracy of the method was evaluated using the verification method of standard addition recovery. The mean recovery rate was $103.54 \%$ (Table 3), which demonstrated that the measured values agreed well with the true values.

3.5. Milk Sample Analysis. All collected breast milk samples were divided into two groups based on the lactation intervals and analyzed with UPLC using the current optimized method. The concentrations of HLF observed throughout the lactation period are shown in Figure 4. The results showed that lactation time significantly influenced HLF concentration, and the concentration observed during lactation time of $\leq 15$ days was significantly higher than that observed with lactation time $>15$ days $(p<0.05)$.

\section{Discussion}

The efficiency of heparin-binding affinity was demonstrated in conjunction with the purification by measuring the recovery of standard LF loaded on the column. The recovery was determined to be nearly $100 \%$, confirming the efficiency of this method. These results indicate that the column was suitable for the isolation and purification of HLF.

In the present study, we demonstrated an optimized method for LF purification employing a heparin affinity column under specific conditions that preserved LF stability. The details of the purification process are as follows: LF was effectively extracted from samples with $100 \mathrm{mmol} / \mathrm{L}$ phosphate buffer at $\mathrm{pH} 5.0$, retained by the heparin affinity column, and eluted using a phosphate buffer with $1.0 \mathrm{~mol} / \mathrm{L}$ $\mathrm{NaCl}$. The choice of the chromatographic column is also crucial for the separation of HLF from other components of the sample. C4 and C18 silica gel columns could be used to separate LF during the selection of chromatographic columns. With more than 20 injections, the C18 column often exhibits excessive baseline noise and spikes and poor reproducibility of the retention time [17]. The C4 column
TABLE 2: Analysis of intra- and interday precisions.

\begin{tabular}{|c|c|c|c|c|c|c|}
\hline $\begin{array}{l}\text { Sample } \\
\text { number }\end{array}$ & \multicolumn{4}{|c|}{ Determined level $(\mathrm{mg} / \mathrm{L})$} & $\begin{array}{c}\text { Mean } \\
(\mathrm{mg} / \mathrm{L})\end{array}$ & $\begin{array}{l}\text { RSD } \\
(\%)\end{array}$ \\
\hline \multicolumn{7}{|l|}{ Intraday } \\
\hline 1 & 747.36 & 741.58 & 724.18 & 724.37 & 734.37 & 1.62 \\
\hline 2 & 1187.42 & 1241.19 & 1242.16 & 1230.26 & 1225.26 & 2.11 \\
\hline 3 & 1214.67 & 1240. & 1252.25 & 1230.46 & 1234.47 & 1.29 \\
\hline \multicolumn{7}{|l|}{ Interday } \\
\hline 4 & & & & & 777.01 & 2.14 \\
\hline 5 & 992.35 & 1012.21 & & & 991.45 & 2.13 \\
\hline 6 & 822.16 & 811.57 & 803.04 & 783.13 & 804.98 & 2.05 \\
\hline
\end{tabular}

The intraday and interday precisions of this method were evaluated by comparing the peak areas obtained on three consecutive days after analyzing the breast milk samples $(n=6)$ spiked with lactoferrin.

TABLE 3: Recovery test results of the method.

\begin{tabular}{lcccc}
\hline $\begin{array}{l}\text { Original level } \\
(\mathrm{mg} / \mathrm{L})\end{array}$ & $\begin{array}{c}\text { Spiked } \\
\text { level } \\
(\mathrm{mg} / \mathrm{L})\end{array}$ & $\begin{array}{c}\text { Determined } \\
\text { level }(\mathrm{mg} / \mathrm{L})\end{array}$ & $\begin{array}{c}\text { Recovery } \\
\text { rate }(\%)\end{array}$ & $\begin{array}{c}\text { RSD } \\
(\%)\end{array}$ \\
\hline & 250 & $1043.93 \pm 8.65$ & 96.52 & 3.58 \\
& 500 & $1316.48 \pm 3.97$ & 102.77 & 0.77 \\
$802.63 \pm 30.98$ & 1000 & $1848.77 \pm 10.48$ & 104.61 & 1.00 \\
& 1500 & $2414.07 \pm 33.01$ & 107.43 & 2.05 \\
& 2000 & $2929.94 \pm 35.38$ & 106.37 & 1.66 \\
\hline
\end{tabular}

Results of recovery tests performed to analyze breast milk samples $(n=5)$ spiked with different concentrations of lactoferrin.

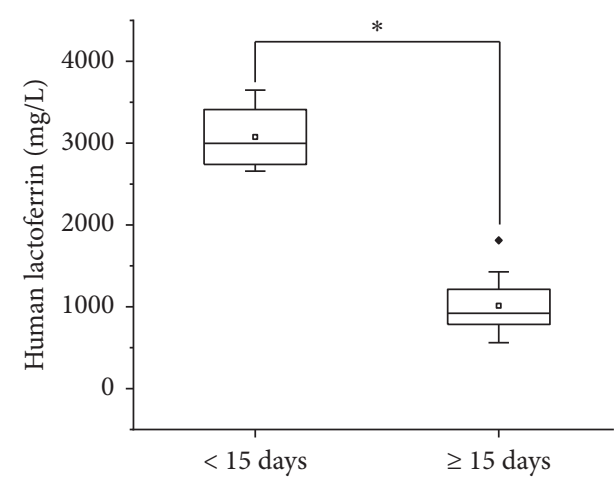

FIGURE 4: Stepwise scatter plot of the lactoferrin content observed at different intervals during the lactation period. Changes in lactoferrin concentrations in breast milk samples during lactation. The symbol in the figure indicates a significant difference $(P<0.05)$ in lactoferrin concentration in breast milk during lactation within 15 days and over 15 days.

demonstrates good peak shape, high recovery, and low levels of protein adsorption, which is suitable for protein analysis [25]. As a result, the widely used C4 column was selected for higher stability and separation efficiency.

Notably, thermal denaturation of LF affected the binding affinity of LF and heparin [17]. Our method estimated the concentration of native LF in human milk. Thermally denatured LF could have been eluted as the sample matrix.

Affinity chromatography is the predominant unit operation performed during large-scale bioprocessing and purification of therapeutic proteins. Affinity chromatography has 
been widely used for the purification of native LF because of its high binding specificity with the target protein. ELISA can be used to detect the native form of proteins with sensitivity at picogram and subpicogram concentrations. The concentration of HLF observed in the present study was similar to that found by Paulaviciene et al. [29], who reported $2.5 \pm 1.07 \mathrm{mg} /$ $\mathrm{mL}$ during 14-16 days. Although ELISA has high sensitivity and versatility, its reproducibility is relatively poor. Hence, few studies have examined the detection of LF by this method. This method did not only detect active LF attributed to the substrate specificity of heparin but also demonstrated better reproducibility than ELISA.

\section{Conclusions}

Here, we described a simple and rapid strategy in which a heparin affinity column was used for the purification of a complex sample containing LF before LF analysis. For optimal purification, several factors that may influence the binding efficiency were investigated. The method was validated in terms of accuracy, precision, LOD, LOQ, and linearity. The results demonstrate the potential for commercial applications of this method for LF analysis.

\section{Data Availability}

The data used to support the findings of this study are available from the corresponding author upon request.

\section{Conflicts of Interest}

The authors declare that there are no conflicts of interest regarding the publication of this paper.

\section{Authors' Contributions}

The first and second authors contributed equally to this manuscript.

\section{Acknowledgments}

The authors thank Zhang Jing, Shen Xing, and others from Junlebao Dairy Co., Ltd. for their help in the operation of their chromatographic instrument. The liquid spectrometry analysis was performed by the Quality Management Center, Junlebao Dairy Co., Ltd. This work was supported by the National Key Research and Development Program of China (no. 2018YFD0501606) and S\&T Program of Hebei, China (nos. 21327110D, 19222812D, and 20327101D).

\section{Supplementary Materials}

Supplementary Table 1: linear relationship of the HLF standard curve under different detection wavelengths. Supplementary Figure 1: standard curve of human lactoferrin $\left(R^{2}=0.9977 ; y=16881 x+161391\right)$. (Supplementary Materials $)$

\section{References}

[1] J. Billakanti, J. McRae, M. Mayr, and K. Johnson, “Advanced analytical tools for bovine lactoferrin identification and quantification in raw skim milk to finished lactoferrin powders," International Dairy Journal, vol. 99, Article ID 104546, 2019.

[2] D. Mudgil and S. Barak, "Dairy-based functional beverages," Milk-Based Beverages, vol. 23, pp. 67-93, 2019.

[3] A. I. Bourbon, J. T. Martins, A. C. Pinheiro et al., "Nanoparticles of lactoferrin for encapsulation of food ingredients," Biopolymer Nanostructures for Food Encapsulation Purposes, vol. 54, pp. 147-168, 2019.

[4] L. Anghel, "Lactoferrin: analysis of the structure profile," Chemistry Journal of Moldova, vol. 9, no. 2, pp. 99-106, 2014.

[5] P. A. Anum Mukhtar Lodhi, "Kainat sajid and zainab zulfiqar, "lactoferrin as nutraceutical protein from milk," Journal of Nutraceuticals and Food Science, vol. 4, pp. 1-5, 2019.

[6] J. Pang, Q. Xiao, H. Yan et al., "Bovine lactoferrin quantification in dairy products by a simple immunoaffinity magnetic purification method coupled with high-performance liquid chromatography with fluorescence detection," Journal of Agricultural and Food Chemistry, vol. 68, no. 3, pp. 892-898, 2020.

[7] M. Czosnykowska-Lukacka, M. Orczyk-Pawilowicz, B. Broers et al., "Lactoferrin in human milk of prolonged lactation," Nutrients, vol. 11, no. 10, 2019.

[8] M. Jahan, N. Francis, and B. Wang, "Milk lactoferrin concentration of primiparous and multiparous sows during lactation," Journal of Dairy Science, vol. 103, no. 8, pp. 7521-7530, 2020.

[9] M. U. Habiba, "A multifunctional marvelous protein in milk," Seminar, vol. 44, 2018.

[10] Z. Yang, R. Jiang, Q. Chen et al., "Concentration of lactoferrin in human milk and its variation during lactation in different Chinese populations," Nutrients, vol. 10, no. 9, 2018.

[11] R. Sharma, "Whey proteins in functional foods," Whey Proteins, pp. 637-663, 2019.

[12] X. Ke, Q. Chen, X. Pan, J. Zhang, W. Mo, and Y. Ren, "Quantification of lactoferrin in breast milk by ultra-high performance liquid chromatography-tandem mass spectrometry with isotopic dilution," RSC Advances, vol. 6, no. 15, pp. 12280-12285, 2016.

[13] E. Tsakali, A. Chatzilazarou, D. Houhoula, S. Koulouris, J. Tsaknis, and J. Van Impe, "A rapid HPLC method for the determination of lactoferrin in milk of various species," Journal of Dairy Research, vol. 86, no. 2, pp. 238-241, 2019.

[14] J. Huang, "Electrochemical immunosensor detection for lactoferrin in milk powder," International Journal of Electrochemical Science, vol. 33, pp. 7816-7826, 2018.

[15] X. Yao, C. Bunt, J. Cornish, S.-Y. Quek, and J. Wen, "Improved RP-HPLC method for determination of bovine lactoferrin and its proteolytic degradation in simulated gastrointestinal fluids," Biomedical Chromatography, vol. 27, no. 2, pp. 197-202, 2013.

[16] M. Chen, F. Wen, Y. Zhang, P. Li, N. Zheng, and J. Wang, "Determination of native lactoferrin in milk by HPLC on HiTrapTM Heparin HP column," Food Analytical Methods, vol. 12, no. 11, pp. 2518-2526, 2019.

[17] Y. Zhang, F. Lou, W. Wu, X. Dong, J. Ren, and Q. Shen, "Determination of bovine lactoferrin in food by HPLC with a heparin affinity column for sample preparation," Journal of AOAC International, vol. 100, no. 1, pp. 133-138, 2017.

[18] A. A. Nahain, V. Ignjatovic, P. Monagle, J. Tsanaktsidis, and V. Ferro, "Heparin mimetics with anticoagulant activity," Medicinal Research Reviews, vol. 38, no. 5, pp. 1582-1613, 2018. 
[19] Y. Gao, K. Wei, J. Li, Y. Li, and J. Hu, "A facile four-armed AIE fluorescent sensor for heparin and protamine," Sensors and Actuators B: Chemical, vol. 277, pp. 408-414, 2018.

[20] A. Lutaty, S. Soboh, S. Schif-Zuck et al., "A 17-kDa fragment of lactoferrin associates with the termination of inflammation and peptides within promote resolution," Frontiers in Immunology, vol. 9, p. 644, 2018.

[21] A. L. Parc, S. Karav, C. Rouquié, E. A. Maga, A. Bunyatratchata, and D. Barile, "Characterization of recombinant human lactoferrin $\mathrm{N}$-glycans expressed in the milk of transgenic cows," PLoS One, vol. 12, no. 2, Article ID e0171477, 2017.

[22] X. Li, Z. Li, E. Xu et al., "Determination of lactoferrin in camel milk by ultrahigh-performance liquid chromatography-tandem mass spectrometry using an isotope-labeled winged peptide as internal standard," Molecules, vol. 24, no. 22, 2019.

[23] F. Carmona, A. González, M. Sánchez et al., "Varying iron release from transferrin and lactoferrin proteins. A laboratory experiment," Biochemistry and Molecular Biology Education, vol. 45, no. 6, pp. 521-527, 2017.

[24] S. Pochet, C. Arnould, P. Debournoux, J. Flament, O. RoletRépécaud, and E. Beuvier, "A simple micro-batch ion-exchange resin extraction method coupled with reverse-phase HPLC (MBRE-HPLC) to quantify lactoferrin in raw and heattreated bovine milk," Food Chemistry, vol. 259, pp. 36-45, 2018.

[25] K. Maes, I. Smolders, Y. Michotte, and A. Van Eeckhaut, "Strategies to reduce aspecific adsorption of peptides and proteins in liquid chromatography-mass spectrometry based bioanalyses: an overview," Journal of Chromatography A, vol. 1358, pp. 1-13, 2014.

[26] S. Telang, "Lactoferrin: a critical player in neonatal host defense," Nutrients, vol. 10, no. 9, 2018.

[27] A. Sreedhara, R. Flengsrud, V. Prakash et al., "A comparison of effects of $\mathrm{pH}$ on the thermal stability and conformation of caprine and bovine lactoferrin," International Dairy Journal, vol. 20, no. 7, pp. 487-494, 2010.

[28] B. Wang, Y. P. Timilsena, E. Blanch, and B. Adhikari, "Lactoferrin: structure, function, denaturation and digestion," Critical Reviews in Food Science and Nutrition, vol. 59, no. 4, pp. 580-596, 2019.

[29] I. J. Paulaviciene, A. Liubsys, A. Eidukaite, A. Molyte, L. Tamuliene, and V. Usonis, "The effect of prolonged freezing and holder pasteurization on the macronutrient and bioactive protein compositions of human milk," Breastfeeding Medicine, vol. 15, no. 9, pp. 583-588, 2020. 